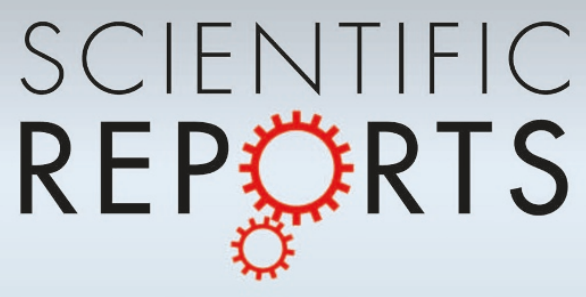

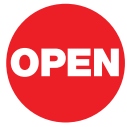

SUBJECT AREAS:

SURFACES, INTERFACES AND THIN FILMS

APPLIED PHYSICS

TWO-DIMENSIONAL MATERIALS

POROUS MATERIALS

Received

14 December 2012

Accepted

7 May 2013

Published

23 May 2013

Correspondence and requests for materials should be addressed to S.M. (smeng@iphy.ac.

$\mathrm{cn})$

\section{Three-dimensional metal-intercalated covalent organic frameworks for near-ambient energy storage}

\author{
Fei Gao, Zijing Ding \& Sheng Meng
}

Beijing National Laboratory for Condensed Matter Physics, and Institute of Physics, Chinese Academy of Sciences, 100190 Beijing, China.

A new form of nanoporous material, metal intercalated covalent organic framework (MCOF) is proposed and its energy storage property revealed. Employing density functional and thermodynamical analysis, we find that stable, chemically active, porous materials could form by stacking covalent organic framework (COF) layers with metals as a gluing agent. Metal acts as active sites, while its aggregation is suppressed by a binding energy significantly larger than the corresponding cohesive energy of bulk metals. Two important parameters, metal binding and metal-metal separation, are tuned by selecting suitable building blocks and linkers when constructing COF layers. Systematic searches among a variety of elements and organic molecules identify Ca-intercalated COF with diphenylethyne units as optimal material for $\mathrm{H}_{2}$ storage, reaching a striking gravimetric density $\sim 5 \mathrm{wt} \%$ at near-ambient conditions $(300 \mathrm{~K}, 20 \mathrm{bar})$, in comparison to $<0.1 \mathrm{wt} \%$ for bare COF-1 under the same condition.

- inding low cost, safe, and efficient energy storage materials has been a major challenge to develop renewable- energy based economy. Hydrogen is considered as an appealing energy carrier alternative to fossil fuels in many applications, because it is abundant, energy intensive, and pollution-free ${ }^{1-3}$. U.S. Department of Energy (DOE) set a target for practical H storage materials to have a gravimetric capacity of 5.5 wt $\%$ by $2017^{4}$. The challenge is to dramatically increase storage capacity and reversibility at ambient conditions ${ }^{5}$. Carbon-based nanostructures and porous materials including fullerene, nanotube, and carbyne networks, have been proposed as potential $\mathrm{H}_{2}$ storage media, thanks to their high surface-to-weight ratios, good reversibility and fast kinetics ${ }^{6-10}$. However, most of them failed at room temperature and ambient pressure due to improper binding to $\mathrm{H}_{2}$.

To reach high and retrievable $\mathrm{H}$ storage at ambient conditions, a light three-dimensional (3D) material with $\mathrm{H}_{2}$ binding energies in the range of $0.2-0.6 \mathrm{eV} / \mathrm{H}_{2}$ is required ${ }^{11,12}$. This implies porous materials must have dense active sites for $\mathrm{H}_{2}$ binding, to which two approaches have been adopted. One is to substitute carbon by other elements such as boron/nitrogen ${ }^{11,13}$; however, it shows little effect and is difficult to apply. The other is to dope light metals including alkali, alkali earth or transition metals, into porous materials ${ }^{14,15}$. Improving metal binding by using nanostructure curvature ${ }^{16,17}$ or incorporation of $\mathrm{sp}$-carbons $\mathrm{s}^{18,19}$ has been also explored. It was found alkali metals have too weak interaction with the substrate and $\mathrm{H}_{2}{ }^{20}$; whereas transition metals tend to cluster on material surface, reducing substantially $\mathrm{H}_{2}$ storage capacity ${ }^{21}$. Upon compromise, calcium is recognized as a superior coating element thanks to its delicate balance of binding strengths to base materials and $\mathrm{H}_{2}{ }^{18,22-24}$. Cacoated fullerene, $\mathrm{Ca}_{32} \mathrm{C}_{60}$, yields strong local electric fields on $\mathrm{C}_{60}$ and reaches a $\mathrm{H}_{2}$ uptake up to $\sim 8.4 \mathrm{wt} \%{ }^{22}$. Cadoped carbyne networks maintain a small distance $\sim 10 \AA$ between metal adsorbates and a high $\mathrm{H}_{2}$ density of $\sim 8$ $\mathrm{wt} \%{ }^{18}$. However, both materials have their own flaws: their $3 \mathrm{D}$ assembly without affecting $\mathrm{H}_{2}$ density is either not achievable or not experimentally demonstrated; and it is difficult to control the position and stability of dopant Ca atoms ${ }^{18,22}$. Similar problems emerge in Ca-doped nanotube, graphite and graphene ${ }^{14,23,24}$.

Covalent organic framework (COF) has been recently synthesized as an important extension of carbon porous materials ${ }^{25,26}$. A variety of experimental studies ${ }^{27,28}$ show that small planar organic molecules form twodimensional (2D) or 3D supramolecular architectures including COFs, through self-assembly of end linker groups, as schematically shown in Figure 1. Due to their adjustable porous structure and unparalleled strength, COFs are very promising for $\mathrm{H}_{2}$ storage. At low temperature $77 \mathrm{~K}$ and high pressure 100 bar, 2D or 3D COFs can currently store 3-7 wt $\% \mathrm{H}_{2}{ }^{27}$. Stunning $\mathrm{H}_{2}$ uptake of $\sim 20 \mathrm{wt} \%$ at $77 \mathrm{~K}$ and 100 bar has been predicted in theoretical simulations for COF-108 and COF-102-3; but it deteriorates quickly to a value below 1-2 wt\% at near ambient condition, for instance, at $300 \mathrm{~K}$ and $20 \mathrm{bar}^{29-31}$. Similar trends were observed for COF-1, a simple layered 


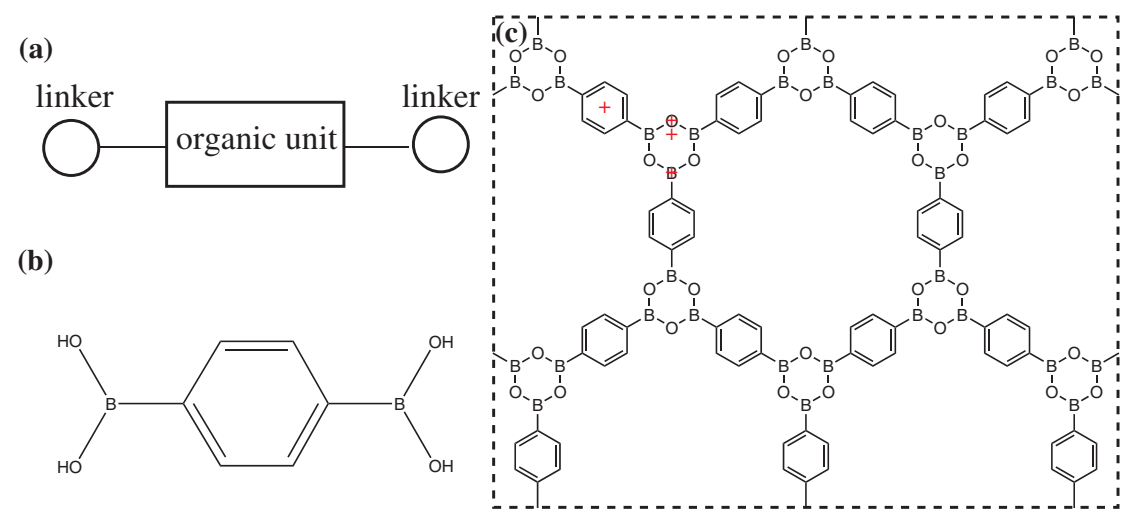

Figure 1 Formation of COFs. (a) Schematic diagram of COF building block composed by two ending linkers and an organic unit, (b) An example of real building blocks: benzene diboronic acid (BDBA), (c) 2D COF formed by BDBA self-assembly, named COF-1. Crosses mark positions tested for metal binding.

COF with the phenyl group as organic unit and boronic acid as the linker (see Fig. 1), shows a $\mathrm{H}_{2}$ density of $1.28 \mathrm{wt} \%$ at $77 \mathrm{~K}$ but it decreases to $\sim 0.08 \mathrm{wt} \%$ at $298 \mathrm{~K}$ and 20 bar in experiment ${ }^{27,32}$. Suitable metal doping also improves $\mathrm{H}_{2}$ storage in $\mathrm{COFs}^{33-38}$. Grand canonical Monte Carlo simulations reveal that $\mathrm{H}$ storage capacity in Li-coated COF-202 can reach 4.39 wt\% at $298 \mathrm{~K}$ and 100 bar, which is three times higher than in undoped COF- $202^{34}$. However, with the increase of $\mathrm{Li}$ concentration, $\mathrm{Li}$ atoms form clusters and $\mathrm{H}$ storage density reduces ${ }^{35}$. Using density functional theory (DFT) calculations, Wu et al. found that both $\mathrm{Li}$ and $\mathrm{Ca}$ forms clusters on COF-10, which are 0.17 and $0.20 \mathrm{eV} /$ atom more stable than scattered atoms, respectively. This reduces storage density from 3 to $1.5 \mathrm{H}_{2}$ per metal atom. Ca dopants provide a stronger bonding to $\mathrm{H}_{2}$ (energy $\sim 0.21 \mathrm{eV}$ ) compared with Li dopants $(0.12 \mathrm{eV})$, due to more charge transfer from $\mathrm{Ca}$ to the substrate ${ }^{35}$. As a remedy, two-step doping, namely, metal decoration on B-substituted COF fragments, was also proposed ${ }^{36}$. On all these successful $3 \mathrm{D}$ reference materials, $\mathrm{H}_{2}$ density is below $1-2 \mathrm{wt} \%$ at near ambient conditions ${ }^{30,31}$. New methods and concepts for further improvement without metal aggregation are key to develop next generation $\mathrm{H}$ storage media.

Here we present a radically different approach to improve $\mathrm{H}$ storage in COFs. We explore the feasibility of using a new class of $3 \mathrm{D}$ network-metal-intercalated COF (MCOF), for near ambient $\mathrm{H}_{2}$ storage. Metal binding in such new class of 3D materials (see the inset of Fig. 2a) has a binding energy significantly larger than that in bulk metals, thus intrinsically blocking metal segregation. Quantum mechanical calculations and thermodynamical analysis reveal that optimized MCOF material stores $4.87 \mathrm{wt} \%$ of $\mathrm{H}_{2}$ at $300 \mathrm{~K}$ and $20 \mathrm{bar}$, greatly enhanced from the value of $<0.1 \mathrm{wt} \%$ for the bare COF- 1 in the same condition ${ }^{32}$.

The paper is organized as follows. After this introduction section, we first expound the idea and important considerations in constructing MCOF in the "Results" section. The feasibility of various light metal elements intercalating in model COF layers, COF-1, is tested. $\mathrm{Ca}$ is identified to be the most suitable gluing metal element. To further improve $\mathrm{H}$ storage performance, we start COF structural optimization through the selection of organic building blocks and linkers. In optimizing organic blocks, small organic molecules as well as polycyclic aromatic hydrocarbons (PAHs) are considered and compared to the reference molecule, benzene. We also investigate the effects of linker groups, where we find $-\mathrm{B}(\mathrm{OH})_{2}$ linkers preserve $\mathrm{H}_{2}$ binding properties of doped organic units. Ca intercalated $\mathrm{COF}$ layers with diphenylethyne organic units (CaCOF-d) are identified as an outstanding $\mathrm{H}$ storage material. After discussing $\mathrm{H}_{2}$ storage properties in 3D CaCOF-d layers at saturation and near ambient conditions, we give a brief discussion on how MCOF can be synthesized experimentally, and present a summary on our major findings.

\section{Results}

It seems natural to combine light metals and extended COF layers for near ambient $\mathrm{H}_{2}$ storage. The two are both light and stable, and can potentially form new framework with dense active sites. In early experiments the newly synthesized COF materials are found to interact weakly with $\mathrm{H}_{2}$ molecules, leading to low storage density at ambient conditions. In the meantime, various theoretical efforts

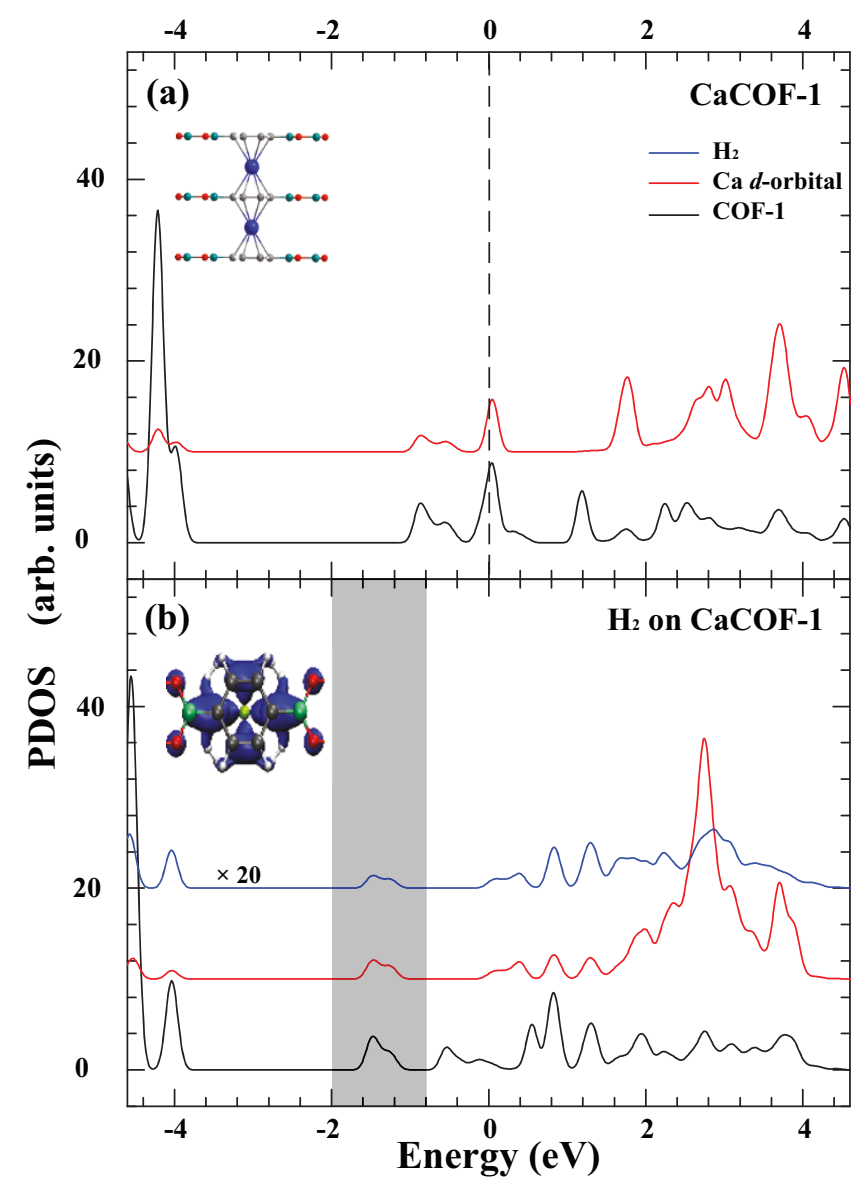

Figure 2| Partial density of states (PDOS) projected onto the COF component (black lines) and the $d$-orbitals of $\mathrm{Ca}$ (red lines) in (a) CaCOF1 and (b) CaCOF-1 after $\mathrm{H}_{2}$ adsorption. The PDOS projected onto $\mathrm{H}_{2}$ blue line, multiplied by 20 times) is also shown in (b). The inset in (a) shows the side view of CaCOF-1, and the inset in (b) shows the charge density associated with the states in the shaded region. 
demonstrated that metal doping cannot effectively improve $\mathrm{H}_{2}$ storage due to metal clustering problem on single COF layers. We start a new approach to explore that whether metal atoms could be intercalated between COF layers to form stable 3D stacks without metal segregation. The choice of workable metal elements and COF materials should be tested to satisfy the requirements of being stable, light, and active for $\mathrm{H}_{2}$ storage.

Constructing metal intercalated $\mathrm{COF}$ for $\mathrm{H}_{2}$ storage. We first take one of the simplest COF materials, COF-1, whose organic unit is a benzene ring and linker boronic acid, as our representative model substrate and investigate its interaction with various metal elements. A range of light metals including $\mathrm{Li}, \mathrm{Na}, \mathrm{Mg}, \mathrm{K}, \mathrm{Ca}$, and $\mathrm{Ti}$ are considered, since they are most commonly adopted to decorate porous nanomaterials serving as active sites for $\mathrm{H}_{2}$ binding. We first test the adsorption site of metal atoms on a single layer COF1. We find metal atoms prefer to adsorb onto the center of the organic unit, a phenyl ring, rather than on top of $\mathrm{B}, \mathrm{O}$, or $\mathrm{B}_{3} \mathrm{O}_{3}$ rings. For instance, the binding energy of $\mathrm{Ca}\left(E_{\mathrm{Ca}}\right)$ on all sites falls in the range of $0.001-0.008 \mathrm{eV}$, except on the center of phenyl ring, which is 0.77 $\mathrm{eV}$. This site preference is a result of Ca interacting with the $\pi$ orbital of phenyl ring, which is absent from the electron rich boroxine ring. As shown later, the energy for Ca binding to the phenyl group in COF is an order of magnitude larger than that on isolated benzene $(0.07$ $\mathrm{eV}$ ), because the $\pi$ orbitals are extended onto neighboring $\mathrm{B}$ atoms connected to phenyl rings in COF and Ca binding is thus enhanced by delocalized $\pi$ electrons, as clearly displayed in Fig. $2 \mathrm{~b}$ inset.

Most importantly, the Ca binding energy increases to $2.83 \mathrm{eV}$ when $\mathrm{Ca}$ and COF-1 layers assemble into multilayered metal intercalation structure, the MCOF. The interlayer distance increases from $3.35 \AA$ to $4.40 \AA$ upon metal intercalation and the stacking manner might also be changed. Ca binding on boroxine rings is $\sim 1 \mathrm{eV}$ less stable than on phenyl rings in intercalated 3D COF layers. We expect metal intercalation takes place simultaneously or with a small barrier through the pores of a diameter of $\sim 10 \AA$ present in COF-1. The Ca binding energy is $3.37 \mathrm{eV}$ if Van der Waals density functional $(\mathrm{VDW}-\mathrm{DF})^{39,40}$ is used to incorporate van der Waals (VDW) interactions; the additional $0.54 \mathrm{eV}$ is attributed to the VDW interactions between adjacent COF layers. For comparison, the cohesive energy in bulk $\mathrm{Ca}$ is $1.88 \mathrm{eV} / \mathrm{Ca}$ in our calculation and the experimental value is $1.86 \mathrm{eV} / \mathrm{Ca}^{40}$, much smaller than Ca binding energy in COFs. The energy for a second $\mathrm{Ca}$ binding around the $\mathrm{Ca}$ on the phenyl ring center is $1.81 \mathrm{eV}$ with a Ca-Ca distance of $3.28 \AA$; the energy is smaller than the binding energy of first $\mathrm{Ca}$ and the cohesive energy of $\mathrm{Ca}$ bulk, showing straightforwardly that $\mathrm{Ca}$ clustering is not favored. Vibrational analysis also confirms that no major negative frequencies occur in the vibrational spectrum of CaCOF-1. Therefore, Ca and COF-1 forms stable 3D materials (referred to as CaCOF-1) via metal intercalation.

Some other metals also work in the same way as Ca to form MCOFs. In Table 1, we list the calculated parameters including the interlayer distance $(L)$ and metal binding energy $\left(E_{\mathrm{M}}\right)$ for metal intercalation COF-1. Metal insertion into the COF layers significantly expands the equilibrium interlayer distances, from $L=3.4 \AA$ for bare $\mathrm{COFs}^{25}$ to $L=5.4 \AA$ for KCOF-1. The binding energies of metals to COFs vary from metal to metal, with $E_{\mathrm{M}}$ for $\mathrm{Mg}$ being smallest $(\leq 0.2 \mathrm{eV})$ and $E_{\mathrm{M}}$ for Ti being largest $(\geq 5.0 \mathrm{eV})$ in our calculations. This is in accord with the rather inert (active) nature of $\mathrm{Mg}(\mathrm{Ti})$ metals. However, both cases have the metal binding energy, $E_{\mathrm{M}}$, smaller than the cohesive energy in bulk metals, $E_{\mathrm{C}}$, as is the case for most metal doped nanostructures previously studied ${ }^{22}$. Surprisingly, on the other hand, $\mathrm{Li}, \mathrm{Na}, \mathrm{K}$ and $\mathrm{Ca}$ metals have $E_{\mathrm{M}}$ significantly larger than the corresponding $E_{\mathrm{c}}$ (see Table 1). This behavior renders metal segregation in such MCOFs thermodynamically unstable. Consequently, 3D network formed in this way is a new class of stable materials without any metal clustering problems.
Table $1 \mid$ Metal binding energies $\left(E_{M}\right)$ and interlayer distances $(L)$ for 3D stacked MCOFs. The cohesive energies $\left(E_{C}\right)$ for bulk metals are also listed for comparison

\begin{tabular}{|c|c|c|c|c|c|}
\hline & \multicolumn{2}{|c|}{ MCOF-1 } & \multicolumn{2}{|c|}{ MCOF-d } & \multirow{2}{*}{$\frac{\text { Bulk metal }}{E_{\mathrm{C}}(\mathrm{eV})}$} \\
\hline & $L(\AA)$ & $E_{M}(\mathrm{eV})$ & $L(\AA)$ & $E_{M}(\mathrm{eV})$ & \\
\hline $\mathrm{Li}$ & 3.7 & 2.289 & 3.9 & 2.231 & 1.605 \\
\hline $\mathrm{Na}$ & 4.6 & 1.408 & 4.7 & 1.490 & 1.048 \\
\hline $\mathrm{Mg}$ & 4.3 & 0.057 & 3.7 & 0.202 & 1.296 \\
\hline K & 5.4 & 1.596 & 5.4 & 1.708 & 0.798 \\
\hline $\mathrm{Ca}$ & 4.4 & 2.830 & 4.4 & 2.786 & 1.877 \\
\hline $\mathrm{Ti}$ & 3.6 & 5.058 & 3.6 & 4.993 & 5.207 \\
\hline
\end{tabular}

The new MCOF material can be approximately viewed as reduced intercalation compounds with metal dopants in cation states. Our Bader charge analysis shows that there are about 1.42 electrons transferred from Ca to COF-1 during CaCOF- 1 formation, and 0.84 electrons transferred from Li to COF-1. This new class of materials contains porous structures with stable, active metal sites, which provide extraordinary advantages for molecular adsorption and storage, in particular, for $\mathrm{H}_{2}$ storage. In this aspect, MCOF as the new class of 3D material is significantly different from earlier proposals including those employing $\mathrm{Ca}_{32} \mathrm{C}_{60}$ and other metal-doped materials, in that:

i) It is an extended three-dimensional framework that can be readily exploited in practical applications; while $\mathrm{Ca}_{32} \mathrm{C}_{60}$ is finite whose $3 \mathrm{D}$ assembly is not feasible without significantly reducing $\mathrm{H}_{2}$ density.

ii) MCOF is thermodynamically stable with metal binding energies greater than that in bulk metals; while on $\mathrm{C}_{60}$, Ca has a binding energy of $1.3 \mathrm{eV}$, significantly smaller than that in bulk $\mathrm{Ca}(1.88$ $\mathrm{eV})^{18,22}$, therefore metal segregation is a severe problem during $3 \mathrm{D}$ assembly.

iii) MCOFs have intrinsic well-ordered pores freely available for $\mathrm{H}_{2}$ diffusion during charge/discharge processes; while $\mathrm{Ca}_{32} \mathrm{C}_{60}$ material does not have this advantage.

The porous MCOF-1 structures with stable, active metal sites are ideal candidates for $\mathrm{H}_{2}$ storage. We employ first-principles DFT to study the interaction between MCOF and $\mathrm{H}_{2}$ molecules, to eliminate uncertainties in $\mathrm{H}_{2}$ binding configuration and energies in empirical calculations. Structure optimization with a full coverage of four intact $\mathrm{H}_{2}$ per metal atom was performed for CaCOF-1 and LiCOF-1. We found that LiCOF-1 fails to bind $\mathrm{H}_{2}$ strongly. The $\mathrm{H}_{2}$ binding energy $\left(E_{\mathrm{b}}\right)$ varies from $\sim 0.05 \mathrm{eV} / \mathrm{H}_{2}$ to $0.02 \mathrm{eV} / \mathrm{H}_{2}$ for a single $\mathrm{H}_{2}$ and for 4 $\mathrm{H}_{2}$ adsorption per $\mathrm{Li}$, due to the fact that $\mathrm{Li}$ is strongly bound to the upper and lower COF-1 layers and the interlayer spacing is rather limited $(3.7 \AA)$. On the other hand, CaCOF-1 can serve as an excellent $\mathrm{H}_{2}$ storage material with the $\mathrm{H}_{2}$ binding energy of 0.13 $\mathrm{eV} / \mathrm{H}_{2}$ with generalized gradient approximation (GGA) exchangecorrelation functional and $0.42 \mathrm{eV} / \mathrm{H}_{2}$ with local density approximation (LDA), corresponding to a gravimetric storage capacity of $4.54 \mathrm{wt} \%$ and volumetric density of $35.2 \mathrm{~g} / \mathrm{L}$ at $0 \mathrm{~K}$, very close to the 2017 DOE target. Using VDW-DF the $\mathrm{H}_{2}$ binding energy to CaCOF1 is $0.18 \mathrm{eV} / \mathrm{H}_{2}$, a reasonable value lying between GGA and LDA numbers, which are known to underestimate and overestimate $E_{\mathrm{b}}$, respectively ${ }^{11}$. Simpler Grimme's DFT+dispersion approach also gives reasonable values for VDW interaction energies between $\mathrm{H}_{2}$ and metal sites in metal organic frameworks ${ }^{41}$. In high-level MP2 and quantum Monte Carlo calculations a binding energy of $\sim 0.2 \mathrm{eV}$ was obtained for $\mathrm{H}_{2}$ binding to partially charged $\mathrm{Ca}$, with basis-sets extrapolated to complete basis limit ${ }^{42,43}$. This number is close to our results. Based on the calculated $\mathrm{H}_{2}$ binding energy, it is shown later the high $\mathrm{H}$ density persists at near-ambient conditions. For comparison, $\mathrm{H}_{2}$ storage capacity of the COF-1 without metal intercalation was found only $1.28 \mathrm{wt} \%$ at $77 \mathrm{~K}$ and ambient pressure, and $0.08 \mathrm{wt} \%$ at $298 \mathrm{~K}$ and 20 bar in experiment ${ }^{32}$. 
The nearly sixty times increase in storage density under near ambient conditions in COF-1 upon $\mathrm{Ca}$ intercalation is attributed to the presence of dense, active metal sites and the ideal binding energy to $\mathrm{H}_{2}$. In CaCOF-1 framework, the empty $\mathrm{Ca} 3 d$ orbitals interact strongly with the $p$ orbitals of COF-1, presenting large density of states (DOS) around the Fermi level, see Fig. 2. These states are saturated upon $\mathrm{H}_{2}$ binding. The energy distribution of $\mathrm{H}_{2}$ orbitals is highly overlapped with Ca $3 d$ orbitals, suggesting $\mathrm{H}_{2}$ binding onto CaCOF-1 via a Kubas mechanism, namely, hybridization between the antibonding $\sigma^{*}$ orbital of $\mathrm{H}_{2}$ and the $d$-orbital of $\mathrm{Ca}^{3,22}$.

Optimizing MCOFs: the organic building blocks. Although CaCOF-1 has shown outstanding property and great promise for $\mathrm{H}_{2}$ storage, it is unclear whether this approach can be extended to other systems, or can be further improved to produce new materials satisfying DOE target of a $5.5 \mathrm{wt} \%$ density. We then explore a range of possible alternatives of organic building units and illuminate the systematic trends in $\mathrm{H}_{2}$ binding behaviors, in the hope to optimize MCOF building blocks for enhanced $\mathrm{H}_{2}$ storage capacity and to identify important parameters for MCOF design.

Benzene as the reference organic unit. To seek an optimal organic building block, the organic unit of COF-1, a benzene ring, was first studied as a standard reference. Ca binding to $\mathrm{C}_{6} \mathrm{H}_{6}$ produces a small energy, $0.07 \mathrm{eV} / \mathrm{Ca}$, less than the binding energy of $\mathrm{Ca}$ to the single layer COF-1, due to limited electron conjugation in isolated benzene molecules. The first $\mathrm{H}_{2}$ adsorbs onto $\mathrm{CaC}_{6} \mathrm{H}_{6}$ in intact form, with $\mathrm{H}$ $\mathrm{H}$ bond length $\left(d_{\mathrm{HH}}\right)$ expanding from 0.749 to $0.785 \AA$. With the increase of the number of adsorbed $\mathrm{H}_{2}$ molecules $(n), \mathrm{H}_{2}$ binding energy and $\mathrm{H}-\mathrm{H}$ bond length both first increase, then decrease, shown in Fig. 3. The maximum averaged $\mathrm{H}_{2}$ binding energy $E_{\mathrm{b}}=$ $0.34 \mathrm{eV} / \mathrm{H}_{2}$ is reached when $n=4$; and the maximum $d_{\mathrm{HH}}$ reaches $0.804 \AA$ at $n=3$. The maximum is not for $n=1$ because of the competition between electron polarization and Pauli repulsion. We note that there is a strong correlation between average $E_{\mathrm{b}}$ and $d_{\mathrm{HH}}$, which might be used to steer optimal design of $\mathrm{H}_{2}$ storage material. PDOS analysis for 1-5 $\mathrm{H}_{2}$ adsorption onto $\mathrm{CaC}_{6} \mathrm{H}_{6}$ clearly indicates there is a largest mixing between $\mathrm{H}_{2}$ states and $\mathrm{Ca} d$-orbitals and a high occupation of $\mathrm{H}_{2}$ antibonding states and $\mathrm{Ca} d$-orbitals for $n=3$ and 4. The sixth $\mathrm{H}_{2}$, initially placed close to $\mathrm{Ca}$, is repelled to a distance larger than $6 \AA$, suggesting the system with five $\mathrm{H}_{2}$ to be saturated. The maximum of five $\mathrm{H}_{2}$ molecules offer 10 electrons, together with 2 electrons from $\mathrm{Ca}$ and $6 \pi$-electrons from benzene, the 18-electron rule is nicely satisfied as proposed for $\mathrm{H}_{2}$ storage on transition metal complexes ${ }^{15}$. The average binding energy is $\sim 0.29$ $\mathrm{eV} / \mathrm{H}_{2}$. For comparison, on Ca-decorated terephthalic acid, $\mathrm{H}_{2}$ binding energy was calculated to be $0.20 \mathrm{eV}$ in GGA and $0.24 \mathrm{eV}$ in MP2 with completed basis set ${ }^{42}$. Among the adsorbed $\mathrm{H}_{2}$ molecules, we observe that $\mathrm{H}_{2}$ prefers to adsorb in the neighborhood of $\mathrm{Ca}-\mathrm{C}_{6} \mathrm{H}_{6}$, than on the top site of $\mathrm{Ca}$. This is also indicated by the difference in binding energies ( 0.11 vs $0.06 \mathrm{eV})$ and $\mathrm{H}-\mathrm{H}$ lengths ( 0.785 vs $0.752 \AA$ ) on the two sites, respectively. It is because the neighboring four molecules interact with $\mathrm{Ca}$ via the Kubas mechanism, as shown in Fig. 4; while the top $\mathrm{H}_{2}$ is bound via the long-ranged electrostatic attraction since no overlap between $\mathrm{H}_{2}$ bound state and $\mathrm{Ca} d$-orbital was observed in $\operatorname{PDOS}^{12}$. Notice that in the case of Ca coated fullerene ${ }^{22}$, the maximal number of adsorbed $\mathrm{H}_{2}$ molecules per $\mathrm{Ca}$ is five with the same trend for $E_{\mathrm{b}}$. The Ca binding energy increases to $0.73 \mathrm{eV} / \mathrm{Ca}$ with two $\mathrm{Ca}$ bound on both sides of benzene, perhaps due to the more polarized $\pi$ orbitals of benzene than the case of single $\mathrm{Ca}$ adsorption. Detailed analysis shows that upon two $\mathrm{Ca}$ adsorption, there are +0.99 electrons transferred from each $\mathrm{Ca}$ to benzene, larger than that for a single $\mathrm{Ca}$ adsorption (+0.88 electrons). The $\mathrm{H}_{2}$ can be adsorbed in total, leading to $\mathrm{H}$ storage capacity of $11.2 \mathrm{wt} \%(0 \mathrm{~K})$, with $d_{\mathrm{HH}}=0.785 \AA$; the $E_{\mathrm{b}}$ of $0.23 \mathrm{eV} / \mathrm{H}_{2}$ falls in the ideal range of $0.2-0.6 \mathrm{eV} / \mathrm{H}_{2}$.

Comparison to other small molecules. Then a series of Cadecorated small organic molecules including $\mathrm{C}_{2} \mathrm{H}_{m}(m=2,4,6)$ and ring structures are investigated. Although some molecules are not yet directly used as COF building blocks, exploring their potential performance yields valuable information for comparison to currently available materials and provides new insights for future applications. Compared with $\mathrm{C}_{6} \mathrm{H}_{6}$, we find $\mathrm{Ca}$ binding to the first three molecules is very weak, with $E_{\mathrm{Ca}} \leq 0.01 \mathrm{eV}$, making them unstable for hosting $\mathrm{H}_{2}$. The binding energy of $\mathrm{Ca}$ to neutral $\mathrm{C}_{5} \mathrm{H}_{5}$ is $3.24 \mathrm{eV}$, showing a strong interaction between them. This is a result of electron deficiency in $\mathrm{C}_{5} \mathrm{H}_{5}$ : to form a stable aromatic system ${ }^{44}, 6 \pi$ electrons are required; where $\mathrm{C}_{5} \mathrm{H}_{5}$ supplies only 5 , with another electron from $\mathrm{Ca}$. Therefore the $\mathrm{CaC}_{5} \mathrm{H}_{5}$ complex formed is a (a)

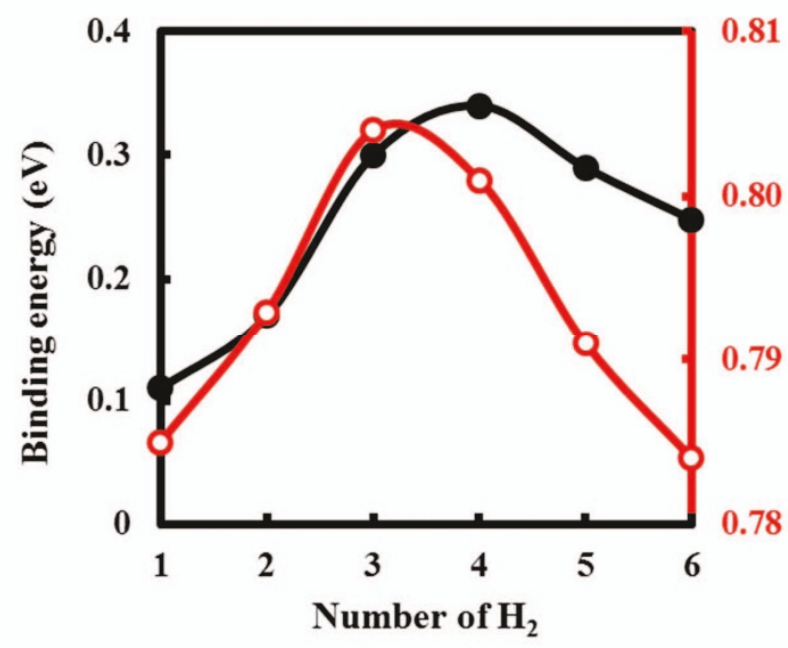

(b)

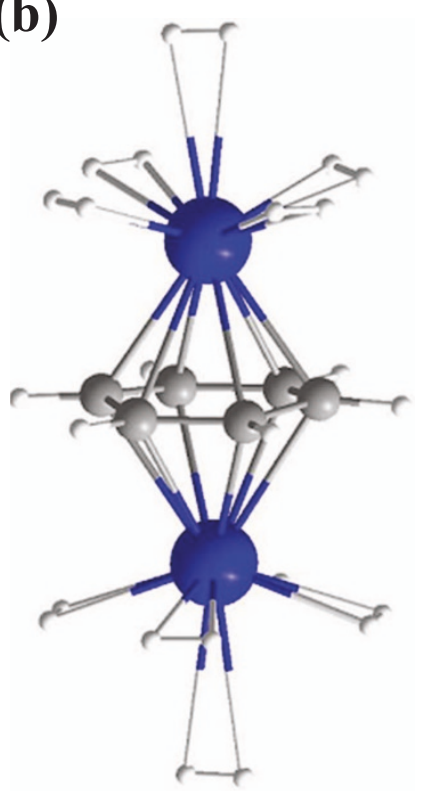

Figure $3 \mid$ (a) Average $\mathrm{H}_{2}$ binding energy $\left(E_{b}\right)$ and $\mathrm{H}-\mathrm{H}$ bond length $\left(d_{\mathrm{HH}}\right)$ as a function of the number of adsorbed $\mathrm{H}_{2}$ on Ca- $\mathrm{C}_{6} \mathrm{H}_{6}$. $($ b) Optimized geometry of ten adsorbed $\mathrm{H}_{2}$ on $\mathrm{Ca}_{2} \mathrm{C}_{6} \mathrm{H}_{6}$. 


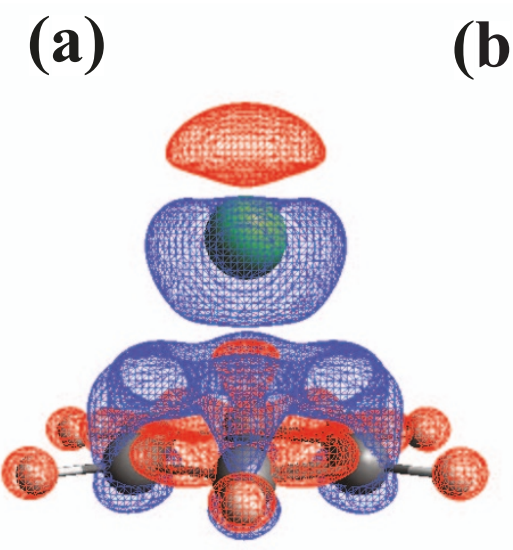

(d)

(e)

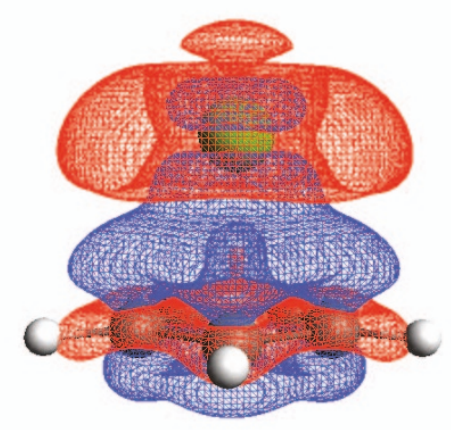

(c)

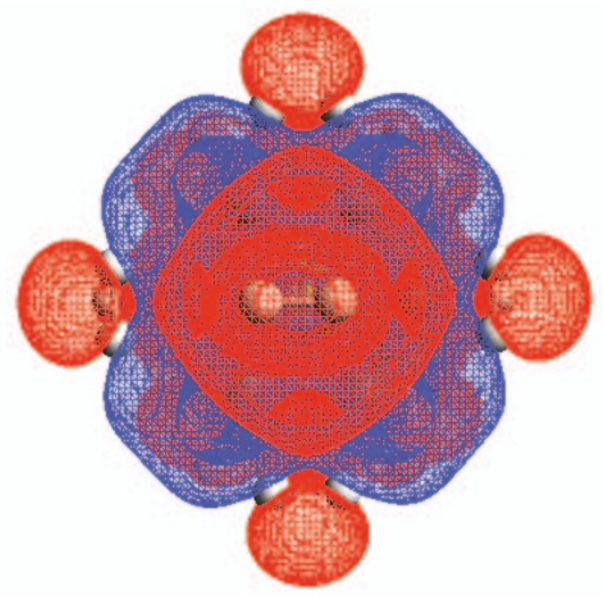

(f)

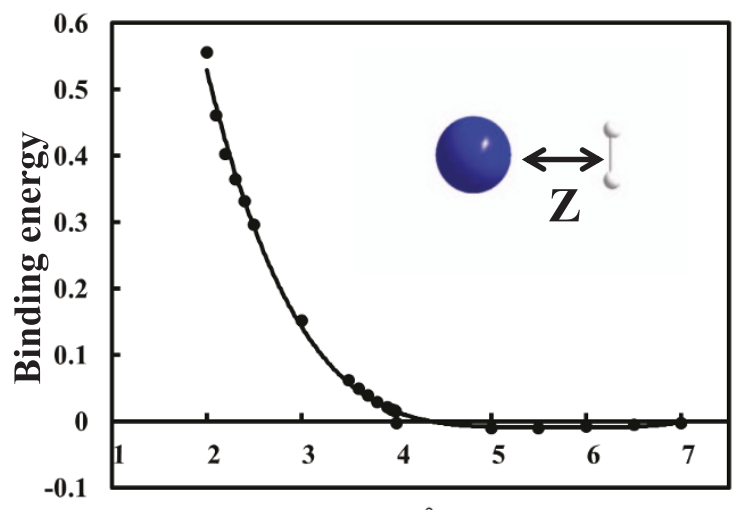

Z ( $($ )

Figure $4 \mid$ (a) Side and (b) top view of charge density difference after Ca binding onto benzene. Isosurfaces with values of $\pm 0.005 e / \AA^{3}$ are shown. Red and blue clouds correspond to electron depletion and accumulation, respectively. (c) Same as (b) but for both two Ca and $10 \mathrm{H}_{2}$ binding to benzene. (d), (e) Same as (a) and (b) but for Ca binding on five-membered $\mathrm{C}_{5} \mathrm{H}_{5}$. (f) The $\mathrm{H}_{2}$ binding energy as a function of distance $(z)$ between $\mathrm{Ca}_{2}$ and $\mathrm{H}_{2}$ on $\mathrm{C}_{5} \mathrm{H}_{5}$.

product of reduction-oxidation chemical reaction, namely, $\mathrm{C}_{5} \mathrm{H}_{5}$ is reduced by an electron from $\mathrm{Ca}$ to form a stable compound. Very surprisingly, the $\mathrm{Ca}-\mathrm{C}_{5} \mathrm{H}_{5}$ seems to be saturated and does not bind any $\mathrm{H}_{2}$. No matter where the $\mathrm{H}_{2}$ molecule is initially placed, it is repelled to a distance $>4 \AA$ from Ca with negligible binding energies $\left(\leq 0.005 \mathrm{eV} / \mathrm{H}_{2}\right)$, shown in Fig. 4(f). It implies the electrostatic force is dominant. This behavior is in contrast to that for $\mathrm{Ca}-\mathrm{C}_{6} \mathrm{H}_{6}$, suggesting that strong interaction between $\mathrm{Ca}$ and the organic component does not necessarily introduce a strong binding to $\mathrm{H}_{2}$; instead, the metal-organic complexes get saturated and become inert to $\mathrm{H}_{2}$ binding. Therefore organic systems with too strong or too weak Ca binding fail to bind $\mathrm{H}_{2}$ well. A good balance between stability (Cabinding) and reactivity (Ca- $\mathrm{H}_{2}$ interaction) is required for optimal $\mathrm{H}_{2}$ storage.

Next, we substitute carbon atoms in benzene by boron or nitrogen, to check whether $\mathrm{H}$ storage properties are affected. Typical structures considered and results are shown in Fig. 5 (first row) and Table 2. We found substitutional structures with more than three $\mathrm{B}$ deform and are unstable, thus are not listed. Ca-doped $\mathrm{C}_{4} \mathrm{H}_{6} \mathrm{~B}_{2}$ and $\mathrm{C}_{4} \mathrm{H}_{4} \mathrm{~N}_{2}$ show much enhancement for the first $\mathrm{H}_{2}$ adsorption, so we study multiple $\mathrm{H}_{2}$ adsorption on them. The two can both host up to five $\mathrm{H}_{2}$. The corresponding $E_{\mathrm{b}}=0.22 \mathrm{eV}$ and $d_{\mathrm{HH}}=0.771 \AA$ for $\mathrm{H}_{2}$ on $\mathrm{CaC}_{4} \mathrm{H}_{6} \mathrm{~B}_{2}$, and $E_{b}=0.14 \mathrm{eV}$ and $d_{H H}=0.784 \AA$ for $\mathrm{CaC}_{4} \mathrm{H}_{4} \mathrm{~N}_{2}$. While they retain similar $\mathrm{H}_{2}$ binding properties as that for $\mathrm{Ca}-\mathrm{C}_{6} \mathrm{H}_{6}$, the Ca-binding is significantly improved, leading to more stabilized material and benign thermodynamical properties without metal clustering. This is due to the fact that the $\mathrm{Ca}-\mathrm{C}_{4} \mathrm{H}_{6} \mathrm{~B}_{2}$ complex is formed by chemical redox reaction, where $\mathrm{Ca}$ electrons are transferred to two-electron deficient $\mathrm{C}_{4} \mathrm{H}_{6} \mathrm{~B}_{2}$ molecule. If we dope two $\mathrm{Ca}$ to $\mathrm{C}_{4} \mathrm{H}_{6} \mathrm{~B}_{2}$ on both sides, ten $\mathrm{H}_{2}$ are adsorbed, with $E_{\mathrm{Ca}}=2.56 \mathrm{eV} / \mathrm{Ca}$, $d_{\mathrm{HH}}=0.771 \AA$, and $E_{\mathrm{b}}=0.17 \mathrm{eV} / \mathrm{H}_{2}$, corresponding to $\mathrm{H}_{2}$ storage density of $11.5 \mathrm{wt} \%(0 \mathrm{~K})$. The experimental route for $\mathrm{B}$-substitution
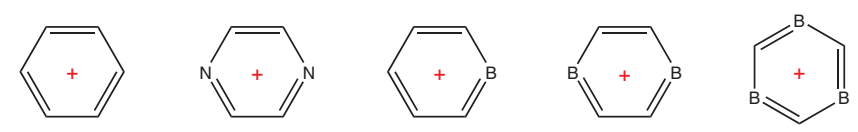

$$
\mathrm{C}_{6} \mathrm{H}_{6}
$$

$$
\mathrm{C}_{4} \mathrm{H}_{4} \mathrm{~N}_{2}
$$

$\mathrm{C}_{5} \mathrm{H}_{6} \mathrm{~B}$

$\mathrm{C}_{4} \mathrm{H}_{6} \mathrm{~B}_{2}$

$\mathrm{C}_{3} \mathrm{H}_{6} \mathrm{~B}_{3}$<smiles>c1ccc2ccccc2c1</smiles>

Naphthalene

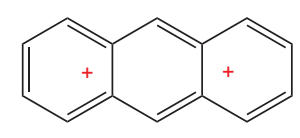

Anthracene

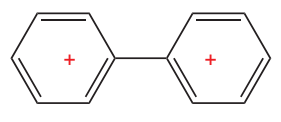

Biphenyl

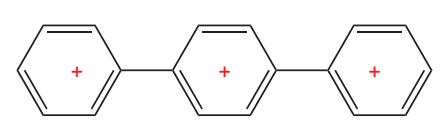

p-Terphenyl

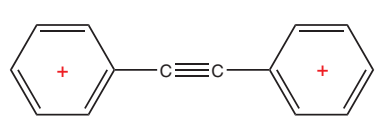

Diphenylethyne
Figure $5 \mid$ A variety of organic molecules serving as COF building units studied in this work. Cross symbols indicate stable positions for $\mathrm{Ca}$ binding. 
Table 2 | Ca binding energy $\left(E_{C a}\right)$, adsorbed $\mathrm{H}-\mathrm{H}$ bond length $\left(d_{H H}\right)$ and energy $\left(E_{b}\right)$ for $\mathrm{H}_{2}$ on six-and five- membered rings

\begin{tabular}{lllllllll} 
& $\mathrm{C}_{6} \mathrm{H}_{6}$ & $\mathrm{C}_{4} \mathrm{H}_{4} \mathrm{~N}_{2}$ & $\mathrm{C}_{5} \mathrm{H}_{6} \mathrm{~B}$ & $\mathrm{C}_{4} \mathrm{H}_{6} \mathrm{~B}_{2}$ & $\mathrm{C}_{3} \mathrm{H}_{6} \mathrm{~B}_{3}$ & $\mathrm{C}_{4} \mathrm{H}_{4} \mathrm{O}$ & $\mathrm{C}_{4} \mathrm{H}_{4} \mathrm{~S}$ & $\mathrm{C}_{4} \mathrm{H}_{5} \mathrm{~N}$ \\
\hline$E_{\mathrm{Ca}}(\mathrm{eV})$ & 0.07 & 0.73 & 3.02 & 3.13 & 4.80 & 0.19 & 0.11 & 0.25 \\
$E_{\mathrm{b}}(\mathrm{eV})$ & 0.11 & 0.15 & 0.01 & 0.35 & 0.02 & 0.20 & 0.27 & 0.35 \\
$d_{H \mathrm{H}}(\mathrm{A})$ & 0.785 & 0.774 & 0.753 & 0.805 & 0.755 & 3.778 & 3.846 & 3.680 \\
\hline
\end{tabular}

might be complicated and their stability requires further investigation. Similar results ${ }^{36,45,46}$ were observed for Ca doping in Bsubstituted metal-organic framework MOF-5 and COF.

We also consider substitution of $\mathrm{C}$ in the five membered rings. Three existing heterocycles, furan $\left(\mathrm{C}_{4} \mathrm{H}_{4} \mathrm{O}\right)$, tetrahydrothiophene $\left(\mathrm{C}_{4} \mathrm{H}_{4} \mathrm{~S}\right)$ and pyrrole $\left(\mathrm{C}_{4} \mathrm{H}_{5} \mathrm{~N}\right)$ are tested. Ca binding energies are $0.10-0.25 \mathrm{eV}$ on these structures, and the first $\mathrm{H}_{2}$ is dissociatively adsorbed on the top of $\mathrm{Ca}$, with $d_{\mathrm{HH}} \geq 3.680 \AA$ (Table 2). Less than two more $\mathrm{H}_{2}$ molecules can be adsorbed further, with the binding energy of $0.1-0.2 \mathrm{eV} / \mathrm{H}_{2}$. They are not suitable for $\mathrm{H}_{2}$ storage.

Large polycyclic aromatic hydrocarbons. Polycyclic aromatic hydrocarbons are formed when two or more benzene rings are connected in the same aromatic plane. The interaction energy between $\mathrm{Ca}$ and the isolated compounds increases to around 1.1 $\mathrm{eV}$, shown in Table 3. In this case, the distance between adjacent $\mathrm{Ca}$ atoms, $d_{\mathrm{Ca}-\mathrm{Ca}}$, is an important parameter. If the distance is too small, it could lead to metal clustering or $\mathrm{H}_{2}$ bound to two $\mathrm{Ca}$ atoms, both reducing $\mathrm{H}$ storage capacity. We found on p-terphenyl $\left(\mathrm{C}_{18} \mathrm{H}_{14}\right)$ $d_{\mathrm{Ca}-\mathrm{Ca}}=4.105 \AA$, and four $\mathrm{H}_{2}$ molecules between adjacent $\mathrm{Ca}$ dissociate by the strong reaction to $\mathrm{Ca}$. With the distance extends to $6.847 \AA$ on diphenylethyne, dissociation of $\mathrm{H}_{2}$ molecules disappears and all $\mathrm{H}_{2}$ are kept intact with $d_{\mathrm{HH}} \simeq 0.782 \mathrm{~A}$. As a result, the total number of twenty $\mathrm{H}_{2}$ are adsorbed on Ca-doped diphenylethyne (five per $\mathrm{Ca}$ ), with a capacity of $10.6 \mathrm{wt} \%(0 \mathrm{~K})$. However, for these isolated molecules, Ca binding energy is smaller than its cohesive energy in bulk, the metal clustering problem might occur if using these isolated compounds for $\mathrm{H}_{2}$ storage.

Optimizing MCOFs: effects of the linker groups. Besides the organic units, linker groups play an essential role in forming COFs via connecting organic units studied above. Two common covalent linkers, $-\mathrm{COOH}$ and $-\mathrm{B}(\mathrm{OH})_{2}$, are usually employed. The carboxylic acid groups form hydrogen-bonded assemblies ${ }^{28}$, while $-\mathrm{B}(\mathrm{OH})_{2}$ groups produce a six-membered ring $\left(\mathrm{B}_{3} \mathrm{O}_{3}\right)$ after sublimation of three water molecules ${ }^{27}$. Five-membered $\mathrm{BO}_{2} \mathrm{C}_{2}$ ring could also form if hydroxyl groups $(-\mathrm{OH})$ are readily available during $\mathrm{COF}$ synthesis ${ }^{27}$.

To investigate the effect of linking groups on $\mathrm{H}$ storage, we add $-\mathrm{COOH}$ and $-\mathrm{B}(\mathrm{OH})_{2}$ to four $\mathrm{Ca}$-decorated compounds, including benzene, biphenyl, p-terphenyl and diphenylethyne. Similar to Cacoated benzene, ten $\mathrm{H}_{2}$ molecules can be stably adsorbed on $\mathrm{Ca}_{2} \mathrm{C}_{6} \mathrm{H}_{4}\left(\mathrm{~B}(\mathrm{OH})_{2}\right)_{2}$. Slight changes in binding energy of $\mathrm{H}_{2}$ from 0.23 to $0.21 \mathrm{eV}$, and in $d_{\mathrm{HH}}$ from 0.785 to $0.787 \AA$ are observed. Ca binding is also improved by $0.203 \mathrm{eV}$, due to $\pi$ electron delocalization from phenyl rings to more electron-negative linker groups. For Cacoated biphenyl, we compare $\mathrm{H}_{2}$ adsorption on compounds with
$-\mathrm{B}(\mathrm{OH})_{2}$ and $-\mathrm{COOH}$ linkers, shown in Table 4. While the former shows little difference from $\mathrm{C}_{12} \mathrm{H}_{10}$ in every respect, the latter enlarges Ca-Ca distance from 3.658 to $4.155 \AA$, leading to the number of adsorbed $\mathrm{H}_{2}$ increasing from 12 to 16 . This is attributed to a stronger interaction between $\mathrm{Ca}$ and phenyl rings when $-\mathrm{COOH}$ linkers are connected to phenyl rings. Therefore, the presence of $-\mathrm{B}(\mathrm{OH})_{2}$ linkers preserves $\mathrm{H}$ storage properties of the original compound, while the - $\mathrm{COOH}$ groups increase the $\mathrm{H}_{2}$ capacity by elongating $\mathrm{Ca}-\mathrm{Ca}$ distances.

We adopt this principle to select linker groups for Ca-decorated PAHs. The Ca-Ca separation on $\mathrm{C}_{18} \mathrm{H}_{10}(\mathrm{COOH})_{4}$ is only a little larger than that on $\mathrm{C}_{18} \mathrm{H}_{14}$ (from 4.105 to $4.244 \AA$ ), but $\mathrm{H}_{2}$ capacity increases greatly, from 18 to $24 \mathrm{H}_{2}$ molecules per unit, shown in Fig. $6(\mathrm{a}, \mathrm{b})$. On the other hand, since the $\mathrm{Ca}-\mathrm{Ca}$ separation is already too large on diphenylethyne $(6.8 \AA)$, we use $-\mathrm{B}(\mathrm{OH})_{2}$ linkers to preserve its $\mathrm{H}_{2}$ storage property. As expected, all parameters such as $E_{\mathrm{Ca}}=0.87 \mathrm{eV}, E_{\mathrm{b}}=0.17 \mathrm{eV}, d_{\mathrm{Ca}-\mathrm{Ca}}=6.9 \AA$, and $d_{\mathrm{HH}}=0.783 \AA$ are very close to the original complex. The same number of $\mathrm{H}_{2}$ molecules is adsorbed. Importantly, both systems have a desirable $\mathrm{H}_{2}$ binding energy of $\sim 0.17 \mathrm{eV} / \mathrm{H}_{2}$. So the $\mathrm{Ca}_{4} \mathrm{C}_{14} \mathrm{H}_{8}\left(\mathrm{~B}(\mathrm{OH})_{2}\right)_{2}$ unit could potentially serve as an optimal building block promising for constructing MCOF to store $\mathrm{H}_{2}$.

Properties of three-dimensional CaCOF-d. The optimization procedures described above identify $\mathrm{Ca}$ intercalated COF structure with diphenylethyne organic unit and $\mathrm{B}_{3} \mathrm{O}_{3}$ linkers, named as COF- $\mathrm{d}$ hereafter, as most promising for $\mathrm{H}_{2}$ storage. Similar to COF-1, COF$\mathrm{d}$ also forms 3D MCOF structures upon intercalation with metal elements such as $\mathrm{Ca}$ and $\mathrm{Li}$, which preserves the ideal $\mathrm{H}_{2}$ storage property in low-dimension materials. We then calculate the equilibrium structure and energy storage properties of the $3 \mathrm{D}$ intercalated CaCOF-d material in a rhombic unit cell with in-plane dimensions of $27.24 \AA \times 27.24 \AA$ and vary its interlayer distance. The unit cell contains three branches of diphenylethyne connected to the center boroxine ring, namely, it consists of 42 carbon atoms, 24 hydrogen atoms, 6 oxygen atoms, 6 boron atoms and 6 calcium atoms before $\mathrm{H}_{2}$ adsorption (see Fig. 7). The optimized interlayer spacing is found to be $4.4 \AA$ for the minimum energy configuration, adopting an eclipsed stacking manner to maximize interlayer interactions. We note the eclipsed stacking is chosen for all COFs with relatively large organic building blocks, with or without metal intercalation ${ }^{25}$. The Ca binding energy in CaCOF-d, with respect to isolated COF-d layer and free $\mathrm{Ca}$ atoms as a reference, is calculated to be $2.79 \mathrm{eV} / \mathrm{Ca}$ (see Table 1), largely exceeding the cohesive energy of $1.88 \mathrm{eV}$ for bulk $\mathrm{Ca}$. This indicates $\mathrm{Ca}$ atoms in this assembly cannot form metal clusters, similar to the case of CaCOF-1. Compared to CaCOF-1, the Ca binding energy is only slightly decreased by

Table 3 | Number of adsorbed Ca atoms $\left(N_{C a}\right)$, average binding energies per $\mathrm{Ca}\left(E_{\mathrm{Ca}}\right)$ and distances between adjacent $\mathrm{Ca}\left(\mathrm{d}_{\mathrm{Ca}-\mathrm{Ca}}\right)$ on representative PAHs. $n$ is the number of adsorbed intact $\mathrm{H}_{2}$ molecules

\begin{tabular}{|cccccc} 
& Naphthalene & Anthracene & Biphenyl & p-Terphenyl & Diphenylethyne \\
\cline { 2 - 6 } & $\mathrm{C}_{10} \mathrm{H}_{8}$ & $\mathrm{C}_{14} \mathrm{H}_{10}$ & $\mathrm{C}_{12} \mathrm{H}_{10}$ & $\mathrm{C}_{18} \mathrm{H}_{14}$ & $\mathrm{C}_{14} \mathrm{H}_{10}$ \\
\hline$N_{\mathrm{Ca}}$ & 4 & 4 & 4 & 6 & 4 \\
$E_{\mathrm{Ca}}(\mathrm{eV})$ & 1.14 & 1.06 & 1.16 & 1.13 & 0.80 \\
$d_{\mathrm{Ca}-\mathrm{Ca}}(\AA)$ & 3.326 & 3.859 & 3.658 & 4.105 & 6.847 \\
$n$ & 8 & 11 & 12 & 18 & 20 \\
\hline
\end{tabular}


Table $4 \mid$ Average binding energy per $\mathrm{Ca}\left(E_{\mathrm{Ca}}\right)$ and the distance between adjacent $\mathrm{Ca}\left(\mathrm{d}_{\mathrm{Ca}-\mathrm{Ca}}\right)$ on biphenyl with or without linker groups. Also shown are total number of adsorbed $\mathrm{H}_{2}$ molecules $(n)$, and their bond lengths $\left(d_{H H}\right)$ and binding energies per $\mathrm{H}_{2}\left(E_{b}\right)$

\begin{tabular}{lccc} 
& $\mathrm{C}_{12} \mathrm{H}_{10}$ & $\mathrm{C}_{12} \mathrm{H}_{8}\left(\mathrm{~B}(\mathrm{OH})_{2}\right)_{2}$ & $\mathrm{C}_{12} \mathrm{H}_{6}(\mathrm{COOH})_{4}$ \\
\hline$E_{\mathrm{Ca}}(\mathrm{eV})$ & 1.16 & 1.25 & 1.46 \\
$d_{\mathrm{Ca}-\mathrm{Ca}}(\AA)$ & 3.658 & 3.695 & 4.155 \\
$n$ & 12 & 12 & 16 \\
$E_{\mathrm{b}}(\mathrm{eV})$ & 0.13 & 0.15 & 0.16 \\
$d_{H H}(\AA)$ & 0.765 & 0.765 & 0.776 \\
\hline
\end{tabular}

$0.04 \mathrm{eV} / \mathrm{Ca}$. Interestingly, Li binding energy in LiCOF-d is also $0.06 \mathrm{eV} / \mathrm{Li}$ smaller than that in LiCOF-1, indicating the diphenylethyne unit is slightly less reactive than single phenyl groups during MCOF formation. Both CaCOF-d and LiCOF-d intercalation are stable $3 \mathrm{D}$ materials.

Three-dimensional stacking in CaCOF-d does not reduce much $\mathrm{H}_{2}$ storage capacity in low-dimensioned clusters and overlayers. In CaCOF-d, a single $\mathrm{Ca}$ can adsorb four intact $\mathrm{H}_{2}$, all parallel to the

(a)

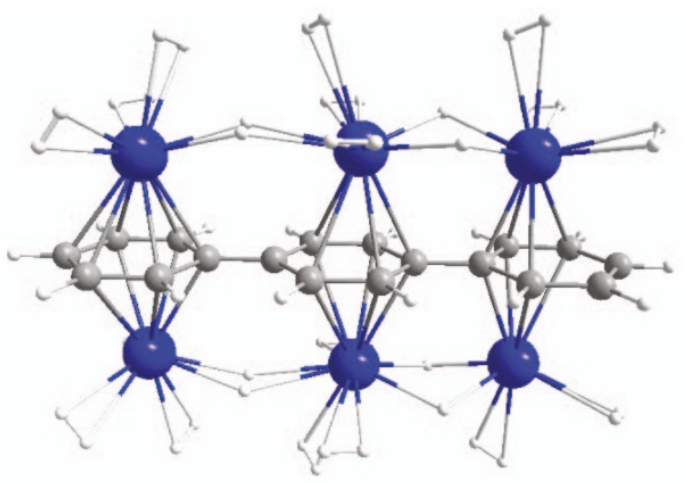

(b)

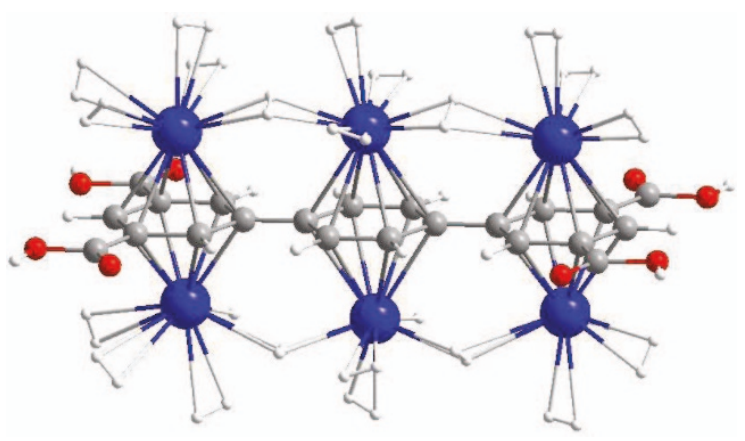

(c)

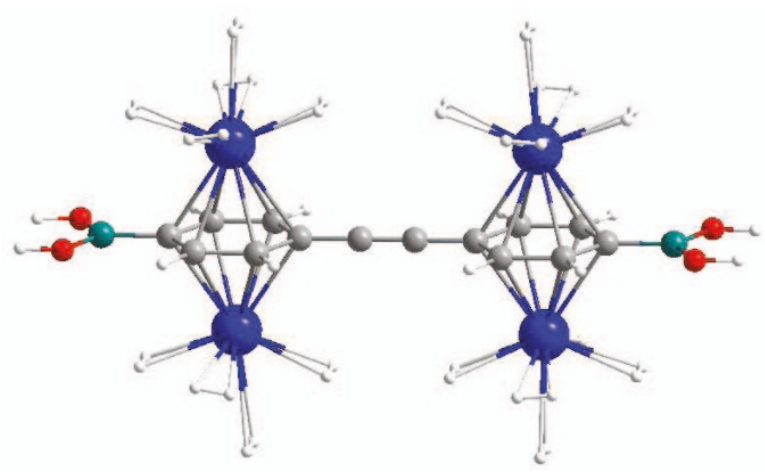

Figure 6 Optimized geometry of (a) $22 \mathrm{H}_{2}$ on $\mathrm{Ca}_{6} \mathrm{C}_{18} \mathrm{H}_{14}$, (b) $24 \mathrm{H}_{2}$ on $\mathrm{Ca}_{6} \mathrm{C}_{18} \mathrm{H}_{10}(\mathrm{COOH})_{4}$, (c) $20 \mathrm{H}_{2}$ on $\mathrm{Ca}_{4} \mathrm{C}_{14} \mathrm{H}_{8}\left(\mathrm{~B}(\mathrm{OH})_{2}\right)_{2}$.

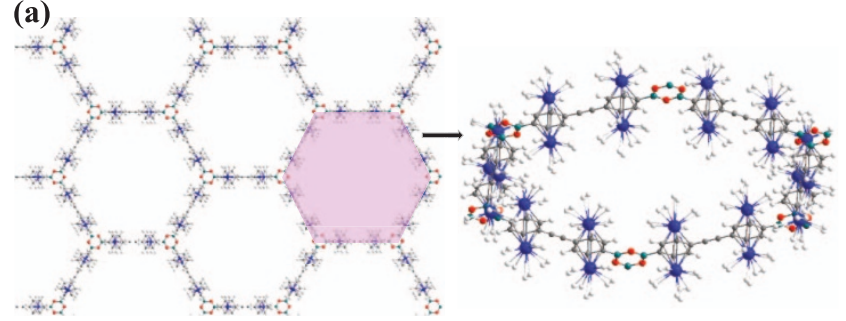

(b)

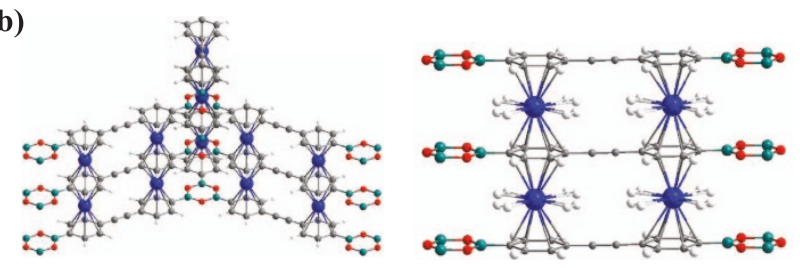

Figure $7 \mid$ (a) $\mathrm{H}_{2}$ storage on two-dimensional Ca-decorated COF-d layer. There are five $\mathrm{H}_{2}$ molecules per Ca adsorbed in 2D CaCOF-d. The hexagonal unit is blown up on the right panel for clarity. (b) Threedimensional CaCOF-d structure in two views. There are four $\mathrm{H}_{2}$ molecules per $\mathrm{Ca}$ adsorbed in 3D CaCOF-d. For clarity $\mathrm{H}_{2}$ molecules are omitted in the left panel.

plane of the COF-d layer, as shown in Fig. $7 \mathrm{~b}$, with the average binding energy $\sim 0.15 \mathrm{eV} / \mathrm{H}_{2}$ in GGA form of exchange-correlation energy and $0.42 \mathrm{eV} / \mathrm{H}_{2}$ in LDA. We believe the exact binding energy
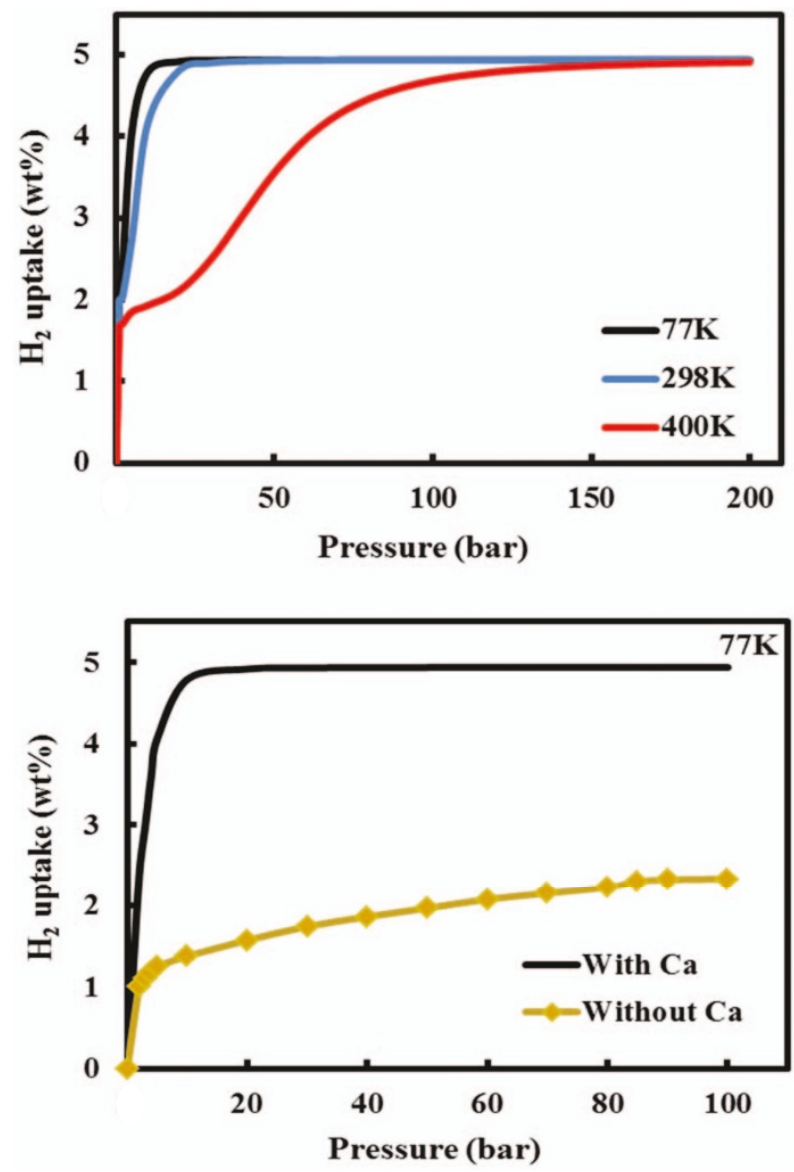

Figure $8 \mid$ (a) $\mathrm{H}_{2}$ storage density of 3D CaCOF-d as a function of pressure at $77 \mathrm{~K}, 298 \mathrm{~K}$, and $400 \mathrm{~K} . \mathrm{H}_{2}$ binding energy around $0.29 \mathrm{eV}$ is used. (b) Comparison of storage density in CaCOF-d (excluding free-volume storage) and bare COF-1 (data from experiments in Ref.27) at $77 \mathrm{~K}$. 
lies between the two values, close to the averaged value at $0.29 \mathrm{eV} / \mathrm{H}_{2}$, based on an empirical guideline that the binding energy averaged from LDA and GGA values is close to the precise Quantum Monte Carlo result for $\mathrm{H}_{2}$ on B-doped fullerene ${ }^{11}$. A storage capacity of 4.94 wt $\%$ at $0 \mathrm{~K}$ is calculated. The distance between two adjacent COF-d layers is $5.0 \AA$ upon $\mathrm{H}_{2}$ binding, enlarged by $0.6 \AA$ compared to $\mathrm{H}_{2}$ free materials. The estimation of $\mathrm{H}_{2}$ density excludes the free volume storage of $\mathrm{H}_{2}$ in the pores of CaCOF-d, which has a diameter of $\sim 20$ $\AA$. If all possible adsorption sites are considered, this porous $3 \mathrm{D}$ network satisfies the 2017 DOE target for $\mathrm{H}_{2}$ storage.

To unveil its practical advantage as a new class of ideal $\mathrm{H}$ storage material, Figure 8 shows the storage capacity of CaCOF-d as a function of pressure and temperature at near ambient conditions. The $\mathrm{H}_{2}$ capacity at a given temperature $T$ and pressure $P$ is evaluated via the relation $f$ (occupation number of adsorbed $\mathrm{H}_{2}$ molecules) $=k T \partial Z /$ $\partial \mu$, where $k$ is Boltzmann constant, $Z$ is the grand partition function, and $\mu$ is the $\mathrm{H}_{2}$ chemical potential ${ }^{47,48}$. The grand partition function follows,

$$
Z=\sum_{g_{l}} \prod_{l} \exp \left\{-g_{l}\left(\varepsilon_{l}-\mu\right) / k T\right\}
$$

where $\varepsilon_{l}$ is the adsorption energy per $\mathrm{H}_{2}$ molecule when the number of adsorbed molecules is $l$, and $g_{l}$ is the multiplicity (degeneracy) of the configuration for a given $l$. The chemical potential of $\mathrm{H}_{2}, \mu$, is given by

$$
\mu(P, T)=\mu^{0}(T)-k T \ln \frac{P}{P^{0}},
$$

where $\mu^{0}(T)$ is standard chemical potential and $P^{0}$ is standard state pressure. Here, $\mu$ and $\varepsilon_{l}$ are negative values. The gravimetric density $\rho$ of hydrogen storage is then obtained as,

$$
\rho(P, T)=\frac{l_{\max }-f(P, T)}{l_{\max }} \times \rho_{\max } .
$$

We adopt ambient pressure $\mu$ values in the literature ${ }^{48}$. At $298 \mathrm{~K}$ and 20 bar, we obtain $4.87 \mathrm{wt} \%$ storage capacity (excluding $\mathrm{H}_{2}$ storage in the free volume), which is substantially large than experimental values for un-doped COF-1 $(0.1 \mathrm{wt} \%)^{32}$. The storage capacity is higher if $\mathrm{H}_{2}$ adsorption onto $\mathrm{B}_{3} \mathrm{O}_{3}$ rings and in free volume is considered. Most of the stored $\mathrm{H}_{2}(3.2 \mathrm{wt} \%)$ will be released at $298 \mathrm{~K}$ and 1 bar (by solely decreasing the pressure), or at $400 \mathrm{~K}$ and 20 bar (by solely increasing the temperature), where about $1.7 \mathrm{wt} \%$ $\mathrm{H}_{2}$ retains. This favors near-ambient condition operation for $\mathrm{H}_{2}$ storage and release, with impressive accessible $\mathrm{H}_{2}$ uptake. Without $\mathrm{Ca}$, the storage capacity is very low (see Fig. 8b), and near-ambient condition operation is not possible due to too small $\mathrm{H}_{2}$ binding energies $\left(\sim 40 \mathrm{meV} / \mathrm{H}_{2}\right)$. The bulk MCOFs formed by Ca intercalation have advantages of being intrinsically three-dimensional, thermodynamically stable, and with well-ordered and adjustable pores, in contrast to previously proposed $\mathrm{Ca}_{32} \mathrm{C}_{60}$ and other Ca-doped nanomaterials ${ }^{22-24}$.

\section{Discussion}

The 3D network based on Ca-decorated carbyne was recently proposed as stable $\mathrm{H}_{2}$ storage media, where Ca binding energy ranges from 1.4 to $2.0 \mathrm{eV} / \mathrm{Ca}$ depending on $\mathrm{Ca}-\mathrm{Ca}$ separation $^{18}$. The $E_{\mathrm{Ca}}$ 's are close to bulk Ca cohesive energy. However, the base material, the 3D carbyne network has yet to be synthesized in experiment. Its existence and room temperature stability (in particular chemical reactivity) remain questionable. On the other hand, crystalline $3 \mathrm{D}$ networks formed by stacking COFs via van der Waals forces have been explicitly demonstrated ${ }^{25}$; we expect Ca-decorated COF-1 to be readily fabricated in experiment, by $\mathrm{Ca}$ intercalation between weakly bound COF-1 layers at high temperatures $(600 \mathrm{~K})$ in Ar gases. Based on existing materials (graphite and metals), a similar approach has resulted the discovery of $\mathrm{CaC}_{6}$, a superconducting material with highest transition temperature of $11.5 \mathrm{~K}$ among metal-intercalated carbon materials ${ }^{49}$. Hydrogen storage on metal intercalated graphite was also explored recently ${ }^{50-53}$. Once formed, the new Caintercalated 3D COF material is thermodynamically stable (characterized by large $\mathrm{Ca}$ binding energy), and would be quite inert, except for $\mathrm{Ca}$ active sites. The metal sites in MCOF might be sensitive to water vapor contamination, as is the case for all other $\mathrm{H}_{2}$ storage materials with active sites; in real applications water concentration must be carefully controlled during $\mathrm{H}_{2}$ charging and discharging processes. Overall, these novel properties would favor MCOF synthesis and $\mathrm{H}_{2}$ storage applications.

In conclusion, we have designed a new class of $3 \mathrm{D}$ networks based on first-principles: metal-intercalated COFs, which have welldefined crystal structures and are chemically active for molecular adsorption. Metal atoms prefer to bind to aromatic organic units rather than $\mathrm{B}_{3} \mathrm{O}_{3}$ connecting rings in MCOFs. $\mathrm{Li}, \mathrm{Na}, \mathrm{K}$ and $\mathrm{Ca}$ could be intercalated into COF-1 and COF-d layers and form thermodynamically stable materials, with metal binding stronger in MCOF than in bulk metals. For $\mathrm{H}_{2}$ storage, $\mathrm{Ca}$ is the most suitable metal to be intercalated in the stacking structures. Important parameters, such as Ca-binding and separation, and trends on 5,6-membered rings and larger PAHs are identified. The covalent linker $-\mathrm{B}(\mathrm{OH})_{2}$ preserves nicely $\mathrm{H}_{2}$ storage properties, while $-\mathrm{COOH}$ linkers adjust Ca separation and in turn $\mathrm{H}_{2}$ store capacity. Systematic optimization of organic building units and linker groups identifies CaCOF-d as most promising for near-ambient $\mathrm{H}_{2}$ storage. The porous $3 \mathrm{D}$ material, CaCOF-d, reaches $\sim 5$ wt $\% \mathrm{H}_{2}$ storage capacity under nearambient conditions without metal clustering problems. Routes for experimental synthesis are discussed. We envisage that this new class of MCOF porous materials, with a high density of active metal sites, would prove useful in a variety of applications including gas adsorption, sensors, and air cleaning.

\section{Methods}

Our first-principles calculations were performed within the framework of density functional theory (DFT) using Vienna ab initio simulation package (VASP) ${ }^{54}$. The ultrasoft pseudopotentials ${ }^{55}$ and general gradient approximation (GGA) in PerdewWang form for exchange-correlation energy ${ }^{56}$ are used. For the cases of hydrogen adsorption in MCOFs, we also use local density approximation (LDA) for comparison ${ }^{57}$. Although GGA tends to underestimate $\mathrm{H}_{2}$ binding energies and LDA overestimates them, the trends for comparing relative energy differences are reliable ${ }^{42,58}$ Recently developed van der Waals density functional (VDW-DF) by Langreth et al. ${ }^{39}$ and parameterized by Klimes et al. $^{40}$ is also employed to check the energies in some critical cases. The binding energies and lengths reported throughout the manuscript are based on GGA exchange-correlation functional unless otherwise specified explicitly. Spin polarization is invoked whenever necessary. We found local magnetic moments are zero for CaCOF systems and very small $\left(<0.3 \mu_{B}\right)$ for Li-COFs and variations in total energy are negligible. The supercells usually contain a vacuum layer of > $10 \AA$ and have cell dimensions of $15 \AA \times 15 \AA \times 15 \AA$ and $30 \AA \times 15 \AA \times 20 \AA$ for small and large finite systems, respectively. A plane wave cutoff of $400 \mathrm{eV}$ and single Gamma for $k$-point sampling are employed for isolated systems. For periodic systems, a rhombic $15.20 \AA \times 15.20 \AA$ unit cell for COF- 1 and $27.24 \AA \times 27.24 \AA$ for COF- $d$ is used within the COF plane, and the interlayer distance is carefully optimized. K-point mesh of $1 \times 1 \times 5$ is used for calculating metal and $\mathrm{H}_{2}$ binding properties of MCOFs. All atoms are allowed to relax until the forces on each atom have magnitudes less than $0.01 \mathrm{eV} / \AA$.

1. Schlapbach, A. \& Züttel, A. Hydrogen-storage materials for mobile applications Nature 414, 353-358 (2001).

2. Steele, B. C. H. \& Heinzel, A. Materials for fuel-cell technologies. Nature 414, 345-352 (2001).

3. Park, N. et al. Progress on first-principles-based materials design for hydrogen storage. Proc. Nat'l Acad. Sci. U.S.A. 109, 19893-19899 (2012).

4. Multi-year research, development and demonstration plan. http:// www.eere.energy.gov/hydrogenandfuelcells/mypp/pdfs/storage.pdf, see Table 3.3.1. Last accessed October 1, 2012.

5. Yuan, F. et al. Complex ammine titanium(III) borohydrides as advanced solid hydrogen-storage materials with favorable dehydrogenation properties. Chem. Mater. 24, 3370-3379 (2012).

6. Liu, C. et al. Hydrogen storage in single-walled carbon nanotubes at room temperature. Science 286, 1127-1129 (1999).

7. Patchkovskii, S. et al. Graphene nanostructures as tunable storage media for molecular hydrogen. Proc. Natl. Acad. Sci. U.S.A. 102, 10439-10444 (2005). 
8. Pupysheva, O. V., Farajian, A. A. \& Yakobson, B. I. Fullerene nanocage capacity for hydrogen storage. Nano Lett. 8, 767-774 (2008).

9. Teprovich, J. A. et al. Synthesis and characterization of a lithium-doped fullerane (Li-x-C-60-H-y) for reversible hydrogen storage. Nano Lett. 12, 582-589 (2012).

10. Yang, S. J. et al. MOF-derived hierarchically porous carbon with exceptional porosity and hydrogen storage capacity. Chem. Mater. 24, 464-470 (2012).

11. Kim, Y. H., Zhao, Y., Williamson, A., Heben, M. J. \& Zhang, S. B. Nondissociative adsorption of $\mathrm{H} 2$ molecules in light-element-doped fullerenes. Phys. Rev. Lett. 96, 016102 (2006).

12. Meng, S., Kaxiras, E. \& Zhang, Z. Y. Metal-diboride nanotubes as high-capacity hydrogen storage media. Nano Lett. 7, 663-667 (2007).

13. Lee, H., Ihm, J., Cohen, M. L. \& Louie, S. G. Calcium-decorated carbon nanotubes for high-capacity hydrogen storage: First-principles calculations. Phys. Rev. B 80, 115412 (2009).

14. Yildirim, T. \& Ciraci, S. Titanium-decorated carbon nanotubes as a potential high-capacity hydrogen storage medium. Phys. Rev. Lett. 94, 175501 (2005).

15. Zhao, Y. F., Kim, Y. H., Dillon, A. C., Heben, M. J. \& Zhang, S. B. Hydrogen storage in novel organometallic buckyballs. Phys. Rev. Lett. 94, 155504 (2005).

16. Chandrakumar, K. R. S., Srinivasu, K. \& Ghosh, S. K. Nanoscale curvatureinduced hydrogen adsorption in alkali metal doped carbon nanomaterials. J. Phys. Chem. C 112, 15670-15679 (2008).

17. Chandrakumar, K. R. S. \& Ghosh, S. K. Alkali-metal-induced enhancement of hydrogen adsorption in C60 fullerene: an ab initio study. Nano Lett. 8, 13-19 (2008).

18. Sorokin, P. B., Lee, H., Antipina, L. Y., Singh, A. K. \& Yakobson, B. I. Calciumdecorated carbyne networks as hydrogen storage media. Nano Lett. 11, 2660-2665 (2011).

19. Srinivasu, K. \& Ghosh, S. K. Graphyne and graphdiyne: promising materials for nanoelec-tronics and energy storage applications. J. Phys. Chem. C 116, 5951-5956 (2012)

20. Sun, Q., Jena, P., Wang, Q. \& Marquez, M. First-principles study of hydrogen storage on Li12C60. J. Am. Chem. Soc. 128, 9741-9745 (2006).

21. Sun, Q., Wang, Q., Jena, P. \& Kawazoe, Y. Clustering of Ti on a C60 surface and its effect on hydrogen storage. J. Am. Chem. Soc. 127, 14582-14583 (2005).

22. Yoon, M. et al. Calcium as the superior coating metal in functionalization of carbon fullerenes for high-capacity hydrogen storage. Phys. Rev. Lett. 100, 206806 (2008).

23. Yang, X., Zhang, R. Q. \& Ni, J. Stable calcium adsorbates on carbon nanostructures: Applications for high-capacity hydrogen storage. Phys. Rev. B 79, 075431 (2009)

24. Lee, H., Ihm, J., Cohen, M. L. \& Louie, S. G. Calcium-decorated graphene-based nanostructures for hydrogen storage. Nano Lett. 10, 793-798 (2010).

25. Cote, A. P. et al. Porous, crystalline, covalent organic frameworks. Science $\mathbf{3 1 0}$, 1166-1170 (2005)

26. El-Kaderi, H. M. et al. Designed synthesis of 3D covalent organic frameworks. Science 316, 268-272 (2007).

27. Furukawa, H. \& Yaghi, O. M. Storage of hydrogen, methane, and carbon dioxide in highly porous covalent organic frameworks for clean energy applications. J. Am. Chem. Soc. 131, 8875-8883 (2009).

28. Blunt, M. O. et al. Guest-induced growth of a surface-based supramolecular bilayer. Nature Chem. 3, 74-78 (2011).

29. Han, S. S., Furukawa, H., Yaghi, O. M. \& Goddard, W. A. Covalent organic frameworks as exceptional hydrogen storage materials. J. Am. Chem. Soc. 130, 11580-11581 (2008).

30. Klontzas, E., Tylianakis, E. \& Froudakis, G. E. Hydrogen storage in 3D covalent organic frameworks. A multiscale theoretical investigation. J. Phys. Chem. C 112, 9095-9098 (2008)

31. Klontzas, E., Tylianakis, E. \& Froudakis, G. E. Designing 3D COFs with enhanced hydrogen storage capacity. Nano Lett. 10, 452-454 (2010).

32. Li, Y. W. \& Yang, R. T. Hydrogen storage in metal-organic and covalent-organic frameworks by spillover. AIChE J. 54, 269-279 (2008).

33. Choi, Y. J., Lee, J. W., Choi, J. H. \& Kanga, J. K. Ideal metal-decorated three dimensional covalent organic frameworks for reversible hydrogen storage. Appl. Phys. Lett. 92, 173102 (2008).

34. Lan, J. H., Cao, D. P. \& Wang, W. C. Li-doped and nondoped covalent organic borosilicate framework for hydrogen storage. J. Phys. Chem. C 114, 3108-3114 (2010)

35. Wu, M. M., Sun, Q., Jena, P. \& Kawazoe, Y. First-principles study of hydrogen adsorption in metal-doped COF-10. J. Chem. Phys. 133, 154706 (2010).

36. Zou, X., Zhou, G., Duan, W. H., Choi, K. \& Ihm, J. A chemical modification strategy for hydrogen storage in covalent organic frameworks. J. Phys. Chem. C 114, 13402-13407 (2010).

37. Sun, Y. Y., Lee, K., Kim, Y.-H. \& Zhang, S. B. Ab initio design of Ca-decorated organic frameworks for high capacity molecular hydrogen storage with enhanced binding. Appl. Phys. Lett. 95, 033109 (2009).
38. Kalidindi, S. B. et al. Metal@COFs: Covalent organic frameworks as templates for Pd nanoparticles and hydrogen storage properties of Pd@COF-102 hybrid material. Chem. Eur. J. 18, 10848-10856 (2012).

39. Dion, M., Rydberg, H., Schroder, E., Langreth, D. C. \& Lundqvist, B. I. Van der Waals density functional for general geometries. Phys. Rev. Lett. 92, 246401 (2004).

40. Klimes, J., Bowler, D. R. \& Michaelides, A. Van der Waals density functionals applied to solids. Phys. Rev. B 83, 195131 (2011)

41. Sillar, K., Hofmann, A. \& Sauer, J. Ab initio study of hydrogen adsorption in MOF5. J. Am. Chem. Soc. 131, 4143-4150 (2009).

42. Sun, Y. Y. et al. Accuracy of density functional theory methods for weakly bonded systems: The case of dihydrogen binding on metal centers. Phys. Rev. B 82, 073401 (2010).

43. Purwanto, W., Krakauer, H., Virgus, Y. \& Zhang, S. W. Assessing weak hydrogen binding on $\mathrm{Ca}+$ centers: An accurate many-body study with large basis sets. J. Chem. Phys. 135, 164105 (2011).

44. Srinivasu, K., Chandrakumar, K. R. \& Ghosh, S. K. Computational investigation of hydrogen adsorption by alkali-metal-doped organic molecules: role of aromaticity. Chem Phys Chem 10, 427-435 (2009).

45. Zou, X. L. et al. Hydrogen storage in Ca-decorated, B-substituted metal organic framework. Int. J. Hydrogen Energy 35, 198-203 (2010).

46. Srinivasu, K. \& Ghosh, S. K. Tuning the metal binding energy and hydrogen storage in alkali metal decorated MOF-5 through boron doping: A theoretical investigation. J. Phys. Chem. C 115, 16984-16891 (2011)

47. Lee, H., Choi, W. I. \& Ihm, J. Combinatorial search for optimal hydrogen-storage nanomaterials based on polymers. Phys. Rev. Lett. 97, 056104 (2006)

48. Lide, D. R. Handbook of Chemistry and Physics, 285-286, CRC Press, New York, (2001).

49. Emery, N. et al. Superconductivity of bulk CaC6. Phys. Rev. Lett. 95, 087003 (2005).

50. Kim, B. J. \& Park, S. J. Optimization of the pore structure of nickel/graphite hybrid materials for hydrogen storage. Int. J. Hydrogen Energy 36, 648-653 (2011).

51. Miyaoka, H., Ishida, W., Ichikawa, T. \& Kojima, Y. Synthesis and characterization of lithiumcarbon compounds for hydrogen storage. J. Alloys Compounds 509, 719-723 (2011).

52. Gunawano, R. The soft hydrogen storage on transition metal graphite intercalates: a density functional theory calculations. Diffusion and Defect Data Part B 170, 379 (2011).

53. Sigal, A., Rojas, M. I. \& Leiva, E. P. M. Is Hydrogen storage possible in metal-doped graphite 2D systems in conditions found on Earth? Phys. Rev. Lett. 107, 158701 (2011).

54. Kresse, G. \& Hafner, J. Ab. initio molecular dynamics for liquid metals. Phys. Rev. B 47, 558-561 (1993)

55. Vanderbilt, D. Soft self-consistent pseudopotentials in a generalized eigenvalue formalism. Phys. Rev. B 41, 7892-7895 (1999).

56. Wang, Y. \& Perdew, J. P. Correlation hole of the spin-polarized electron gas, with exact small-wave-vector and high-density scaling. Phys. Rev. B 44, 13298-13307 (1991).

57. Ceperley, D. M. \& Alder, B. J. Ground state of the electron gas by a stochastic method. Phys. Rev. Lett. 45, 566-569 (1980).

58. Srepusharawoot, P. et al. Ab Initio study of molecular hydrogen adsorption in covalent organic framework-1. J. Phys. Chem. C 113, 8498-8504 (2009).

\section{Acknowledgments}

This work is partially funded by the innovation plan (energy project cluster) and hundred-talent program of CAS, NSFC (grant 11074287 and 11222431) and MOST (grant 2012CB921403).

\section{Author contributions}

S.M. conceived the idea and carried out theoretical analysis. F.G. performed most of the numerical simulations. Z.D. carried out some numerical simulations and theoretical analysis. S.M. and F.G. analyzed the data and wrote the paper. All authors discussed the results and commented on the manuscript.

\section{Additional information}

Competing financial interests: The authors declare no competing financial interests.

License: This work is licensed under a Creative Common

Attribution-NonCommercial-NoDerivs 3.0 Unported License. To view a copy of this license, visit http://creativecommons.org/licenses/by-nc-nd/3.0/

How to cite this article: Gao, F., Ding, Z. \& Meng, S. Three-dimensional metal-intercalated covalent organic frameworks for near-ambient energy storage. Sci. Rep. 3, 1882; DOI:10.1038/srep01882 (2013) 